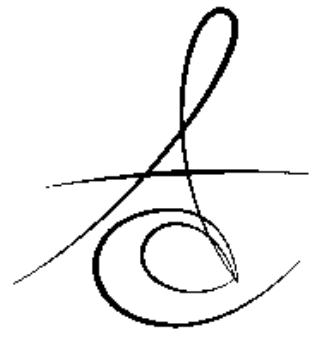

Makale Kodu/Article code: 1164

Makale Gönderilme tarihi: 06.05.2013

Kabul Tarihi: 25.06.2013

\section{FİBRÖZ DİSPLAZİ: BİR OLGU SUNUMU}

\section{FIBROUS DYSPLASIA: A CASE REPORT}

\author{
Doç. Dr. Binali ÇAKUR* \\ Prof. Dr. O. Murat BİLGE*
}

\section{ÖZET}

ile kliniğimize müracaat etti. Konik ışınlı bilgisayarlı tomografi ile yapılan incelemede sol maksiller kemikte bukkal ve lingual genişleme gösteren, maksiler sinüs ile ilişkili, ekspansil, dens bir lezyon ve düzensiz kemik oluşum alanları izlendi. Bu vaka raporunda monostotik fibröz displazinin ayrıntılı görüntülemesini sunmayı amaçladık.

Anahtar Kelimeler: fibröz displazi , maksilla, konik ışınlı bilgisayarlı tomografi

\section{GİRİ̧̧}

1938'de Lichtenstein tarafından tanımlanan fibröz displazi (FD); etyolojisi bilinmeyen, normal kemiğin yerini yapısal olarak zayıf fibröz ve osseöz dokunun aldığı benign bir kemik hastalığıdır. ${ }^{1,2}$ Tek bir kemiği tutan (genellikle kaburga veya kraniofasial kemiklerden sadece biri), en sık görülen ve en hafif şekli olan (\%70-80) monostotik FD; birçok sayıda kemiği etkileyen (sıklıkla ekstremitelerin uzun kemikleri, pelvis ve kaburga kemiklerinden ikisini veya daha fazlası) ve daha seyrek görülen (\%20-25) poliostotik FD ve ciddi kraniofasial ve iskelet tutulumun olduğu poliostotik fibröz displazinin yanında endokrin bozukluklar, kutanöz hiperpigmentasyonun olduğu ve çok nadir görülen McCune-Albright sendromu olmak üzere üç klinik tipi vardır. ${ }^{1-4}$ Bir tipten diğerine dönüşme henüz bildirilmemiştir. ${ }^{1,5}$ Adolesan ve genç erişkinlerde daha sık olmak üzere monostotik ve poliostotik formlar her iki cinste eşit görülürken, McCune-Albright sendromu özellikle kadınlarda sık görülür. ${ }^{2,3}$ Genellikle kemik büyümesi ağrısız bir şişlik halinde olur. ${ }^{2}$ Radyografide fibröz ve kemik yapıların oranına bağlı olarak, radyolusent ve sklerotik alanlar şeklinde gözlenir. ${ }^{2,6} \mathrm{Bu}$ vakada sol maksiller bölgede oluşan bir fibröz displazi olgusu sunuldu.

\section{ABSTRACT}

Fibrous dysplasia is a benign bone disease. 27year-old female patient was admitted to our clinic with swelling of the left maxillary region. In examination with cone beam computed tomography, a lesion which is causing expansion in the buccal and lingual, associated with maxillary sinus, irregular borders, homogeneous density were detected in the left maxillary region. In this report, it is aimed to present detailed the imaging of a case of monostotic fibrous dysplasia.

Key word: fibrous dysplasia, maxilla, cone beam computed tomography

\section{OLGU SUNUMU}

27 yaşındaki kadın hasta, sol maksiller bölgedeki şişlik nedeni ile kliniğimize başvurdu. Anamnezde şişliğin uzun süredir var olduğu, büyüklüğünde artış olduğu ve yüzündeki bu şişlikten rahatsız olduğu tespit edildi. Ayrıca, mevcut bir sistemik hastalığının olmadığı ve herhangi bir ilaç kullanmadığı tespit edildi. Deformite ve fasial asimetri haricinde herhangi bir belirti veya bulgusu yoktu. Detaylı inceleme amacıyla konik ışınlı bilgisayarlı tomografi (KIBT) (NewTom-FP; Quantitative Radiology, Verona, Italy) çekildi. Cihaz, standart olarak 110 kVp ve maksimum 15 mA konik ışın hüzme tekniği ile çalışmaktadır. Cihaz hastanın baş yoğunluğuna göre otomatik olarak doz seçimini sağlayan bir sisteme (AEC, automatic exposure control system) sahiptir. Cihazın gantri açısı sabit ve yere dik olduğundan, aksiyal planda KIBT incelemesi yapıldı. Aksiyal plan, hastada oksipitomeatal hatta veya sert damağa paralel

* Atatürk Üniversitesi, Diş Hekimliği Fakültesi, Ağız, Diş ve Çene Radyolojisi Anabilim Dalı "Bu çalışma oral Diagnoz ve maksillofasial radyoloji derneği v. Bilimsel sempozyumunda (33 pp., Erzurum, Türkiye, 2013) poster olarak sunulmuştur. 
Atatürk Üniv. Diş Hek. Fak. Derg.

J Dent Fac Atatürk Uni

Supplement: 8, Yll: 2014, Sayfa : 1-3
ÇAKUR, DURMA, BİLGE , YILDIRIM pozisyonda yatırıldı. Bas, sert damak yere dik olacak şekilde ayarlandı. İnceleme alanı, tarama başlangıcında alınan KIBT rehber imaj üzerinden ayarlandı. KIBT inceleme; kesit kalınlığı $0.5 \mathrm{~mm}$ aksiyal, inceleme alanı düseyde $13 \mathrm{~cm}$ ve yatayda 17 $\mathrm{cm}$ olarak ayarlandı. Konik ışınlı bilgisayarlı tomografisinde sol maksiller kemikte, 12 - 18 numaralı dişler arasında, maksiller kemikte bukkal ve lingual genişleme gösteren ve bombeliğe yol açan, maksiler sinüs ön ve alt duvarını da içerisine alan, ekspansil, dens bir lezyon ve düzensiz kemik oluşum alanları izlendi. (Resim 1). Hastanın yapılan biyopsisinin histopatolojik incelenmesinde fibröz displazi rapor edildi.

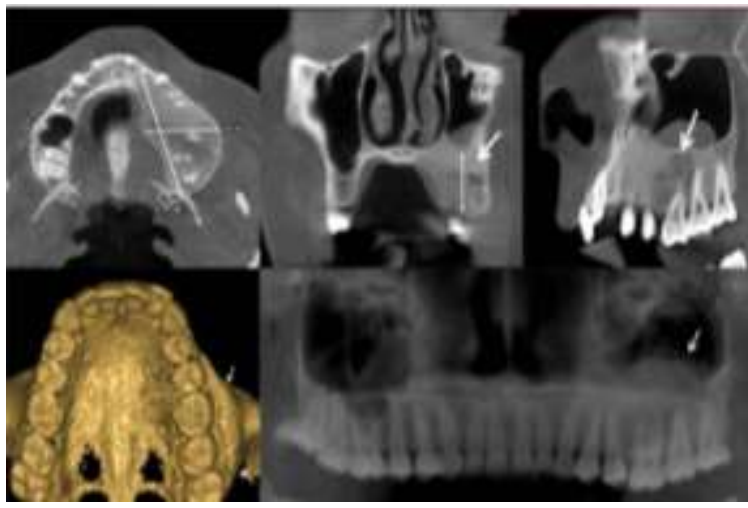

Resim 1. Konik ışınlı bilgisayarlı tomografide sol maksiller kemikte $26 \times 46.3 \times 17.4 \mathrm{~mm}$ ebatlarında ekspansil, dens bir lezyon ve düzensiz kemik oluşum alanları (Beyaz oklar).

\section{TARTIŞMA}

Fibröz displazinin kraniofasial bölgede en sık görüldüğü yer pek çok araştırmada farklılık arz eder..$^{2,3,7-9}$ Bununla birlikte maksilla ve mandibula başboyun bölgesinde en sık tutulan alanlardır. ${ }^{1}$ Ayrıca kraniofasial bölge tutulumu monostotik FD'li hastalarda poliostotik FD'li hastalara (\%40-60) göre daha az görülmesine rağmen (\%10-25) kraniofasial FD'li hastaların çoğu monostotiktir. ${ }^{2-4,6,7}$ Vakamız 27 yaşındaki kadın hastada görülen maksiller kemik tutulumu olan yaklaşık 26×46×17 mm ebatlarında bir monostotik FD vakasıydı. Klinik olarak monostotik form en hafif formdur ve daha çok 20-30 yaşlar arasında görülür. Genellikle asemptomatiktir ve başka sebeplerle istenmiş radyolojik incelemelerde daha sık tespit edilir. ${ }^{1-3}$ FD'nin maligniteye ( daha sık osteojenik sarkom ve fibrosarkom ) dönüşme intimali $\% 0.5^{\prime}$ tir ve bu durum özellikle radyoterapi alanlarda görülür. ${ }^{1,4,6,10}$ Lezyon genişleyerek büyür ve nazal fossa, paranazal sinüsler, orbita veya internal akustik kanal gibi diğer anatomik yapılarda fonksiyonel bozukluklara yol açabilir. ${ }^{1,2}$ Bununla birlikte lezyonun büyümesi pubertede duraklayabilir. ${ }^{2,4,6}$ Vakamızda maksiller kemikte ekspansiyon gösteren ve bombeliğe yol açan, maksiler sinüs ön ve alt duvarını da içerisine alan fakat sinüs tutulumunun olmadığı alanlar izlendi (Resim 1,2). Tanıda radyolojik bulgular oldukça faydalıdır. Günümüzde daha çok BT ve MRI tercih edilir. BT kemik detayları ve lezyon sınırlarını göstermede, ayırıcı tanıda ve hastalığın seyrini takipte oldukça avantajlıdır. ${ }^{5,11,12}$ Radyolojik olarak mineralizasyon derecesiyle ilişkili radyolusent (basit kemik kistinden ayırımı zor), buzlu cam (fibröz ve kemik yapılar eşit oranda) ve sklerotik (kemik dokuları belirgin) görünümlerde olabilir. ${ }^{13}$ Hastamızda kemik dokuların yoğun olduğu sklerotik görünüm baskındı. MRI yumuşak doku komponentlerinin değerlendirilmesinde ve ayırıcı tanısında faydalıdır. ${ }^{11,14}$ Radyolojik bulgular karakteristik olup, patognomonik değildirler; bu yüzden kesin tanı için biyopsi ile histopatolojik değerlendirme gerekir. $^{2,4}$ Tedavisinde konservatif yaklaşımlar uygulanmalıdır. Cerrahi tedavi progresif deformiteler, ciddi fonksiyonel bozukluklar veya malign transformasyon görüldüğünde tercih edilmelidir. ${ }^{1,2}$

\section{KAYNAKLAR}

1. Livaoğlu M, Bahadır O. Maksiller Sinüste Fibröz Displazi: Olgu Sunumu, Tanı ve Tedavi Yönünden Literatürün İrdelenmesi. F.Ü.Sağ.Bil.Tıp Derg 2010: 24: 59 - 61

2. Şengör A, Koç $A$, Han T. Maksiller fibröz displazi. KBB-Forum 2004;3:92-4.

3. Espinosa JM, Elizalde A, Aquerreta JD, Alcalde J, Zubieta JL. Fibrous dysplasia of the maxilla. Ann Otol Rhinol Laryngol 1998;107:175-7.

4. Mladina R, Manojlovic S, Glavas DM, Heinrich Z. Isolated unilateral fibrous dysplasia of the sphenoid sinus. Ann Otol Rhinol Laryngol 1999; 108:1181-4.

5. Özbek C, Aygenç E, Fidan F, Ünsal E, Özdem C. Fibrous dysplasia of the temporal bone. Ann Otol Rhinol Laryngol 2003; 112: 654-6. 
6. Mueller DP, Dolan KD, Yuh WTC. Fibrous dysplasia of the sphenoid sinus. Ann Otol Rhinol Laryngol 1992;101:100-1.

7. Assaf AT, Benecke AW, Riecke B, Zustin J, Fuhrmann AW, Heiland $M$, et al. Craniofacial fibrous dysplasia (CFD) of the maxilla in an 11year old boy: A case report. J Craniomaxillofac Surg. 2012;40:788-92.

8. Ogusthorpe JD, Gudeman SK. Orbital complications of fibrous dysplasia of the skull. Otolaryngol Head Neck Surg 1987;97:403-405.

9. Ferguson BJ. Fibrous Dysplasia of the paranasal sinuses. Am J Otolaryngol 1994;15:227-30.

10. Edgerton MT, Persing JA, Jane JA. The surgical treatment of fibrous dysplasia. With emphasis on resent contributions from craniomaxillofacial surgery. Ann Surg 1985; 202: 459-79.

11. Lusting LR, Holliday MJ, McCarty EF, Nager GT. Fibrous dysplasia involving the skull base and temporal bone. Arch Otolaryngol Head Neck Surg 2001; 127: 1239-47.

12. d'Archambeau O, Parizel PM, Koekelkoren E, Van de Heyning P, De Schepper AM. CT diagnosis and differential diagnosis of otodystrophic lesions of the temporal bone. Eur J Radiol 1990; 11: 2230.

13. Menon S, Venkatswamy S, Ramu V, Banu K, Ehtaih S, Kashyap VM.Craniofacial fibrous dysplasia: Surgery and literature review. Ann Maxillofac Surg. 2013;3:66-71.

14. Rojas R, Palacios E, Kaplan J, Wong LK. Fibrous dysplasia of the frontal sinus. Ear Nose throat J 2004; 83; 14-5.

\author{
Yazışma Adresi \\ Binali ÇAKUR \\ Atatürk Üniversitesi \\ Diş Hekimliği Fakültesi \\ Ağız, Diş ve Çene Radyolojisi \\ 25240, Erzurum, Türkiye. \\ E-mail: bcakur@atauni.edu.tr \\ Fax no: +90 4422360945 \\ Telephone : +90 4422311765
}

